\title{
Calculation of the Vertical Strata Load of Utility Tunnel Crossing Ground Fissure Zone
}

\author{
Dan Zhang, ${ }^{1}$ Zhiping Hu ${ }^{1},{ }^{1,2}$ Ganggang Lu, ${ }^{1}$ Rui Wang, ${ }^{1}$ and Xiang Ren ${ }^{1}$ \\ ${ }^{1}$ School of Civil Engineering, Chang'an University, Xi'an 710061, China \\ ${ }^{2}$ Institute of Underground Structure and Engineering, Chang'an University, Xi'an 710061, China \\ Correspondence should be addressed to Zhiping Hu; huzhping@chd.edu.cn
}

Received 22 July 2020; Revised 16 November 2020; Accepted 25 November 2020; Published 8 December 2020

Academic Editor: Junyan Yi

Copyright (c) 2020 Dan Zhang et al. This is an open access article distributed under the Creative Commons Attribution License, which permits unrestricted use, distribution, and reproduction in any medium, provided the original work is properly cited.

A ground fissure is a geological disaster in which the vertical dislocation of strata causes surface rupture. Ground fissures can cause extreme harm to the surface and underground buildings. Ground fissure activity can result in different settlement on the two sides of the strata, which will generate additional stress (pressure) that differs from the stress of the general stratum on underground structures across the ground fissure zone. It is essential to assess the effective stress of strata in the design of underground engineering structures across a ground fissure zone. The Xi'an ground fissure through a utility tunnel was focus of the research, and a physical model and data for oblique crossing of the $45^{\circ}$ ground fissure were analyzed. A model of the utility tunnel structure was established, including the surrounding soil load as an active ground fissure environment. This model was used to calculate the vertical formation pressure of the overlying soil on the utility tunnel. A method to calculate the overlying load on the utility tunnel caused by ground fissure activity was proposed and compared with the calculation based on the A. Marston principle. The results showed that the ground fissure load calculation method based on the strata-holding effect can effectively calculate the earth pressure of the surrounding soil layer of the utility tunnel in the cross-ground fissure section. The results of this work provide guidance and reference value for the design of a utility tunnel in an area with the potential for a ground fissure.

\section{Introduction}

Ground fissures are serious geological hazards and have occurred in many parts of the world, including the United States, China, Australia, and many African countries. Ground fissures were first reported in China in the 1950s and can cause damage to roads, buildings, and pipelines [1-9]. In Shandong, Anhui, Jiangsu, Shanxi, Shaanxi, and Henan provinces, ground fissures are important considerations in city planning, with many ground fissures active in these regions [10-21].

Ground fissures arise from the development of fault structure and the excessive exploitation of groundwater $[7,13,18]$. Since the 1950s, excessive extraction of groundwater has contributed to 14 ground fissures in Xi'an $[3,16]$. The emergence of ground fissure zones has caused the destruction of many surface buildings and underground construction facilities, resulting in billions of direct economic losses in Xi'an. Existing ground fissures continue to develop and new ground fissures form, seriously restricting urban construction planning for the effective use of the land in Xi'an and presenting a significant safety hazard for urban construction $[16,22-24]$. The general trend of the $\mathrm{Xi}$ 'an ground fissure is $\mathrm{EN} 65^{\circ} \sim \mathrm{EN} 85^{\circ}$ [25]. Unlike surface buildings or structures, a utility tunnel is a long linear structure, which must sometimes cross an active ground fissure but still meet the requirements of structural safety after completion. The layout of the Xi'an utility tunnel and the shape of the ground fissure are presented in Figure 1.

Previous research on ground fissures focused on field investigation, evaluation, monitoring, physical model tests, and theoretical simulations. When designing the structure of a utility tunnel that must cross a ground fissure, as with subway tunnels, the ground load is typically calculated according to the design specifications and with consideration of the weight of all soil columns above the cross 


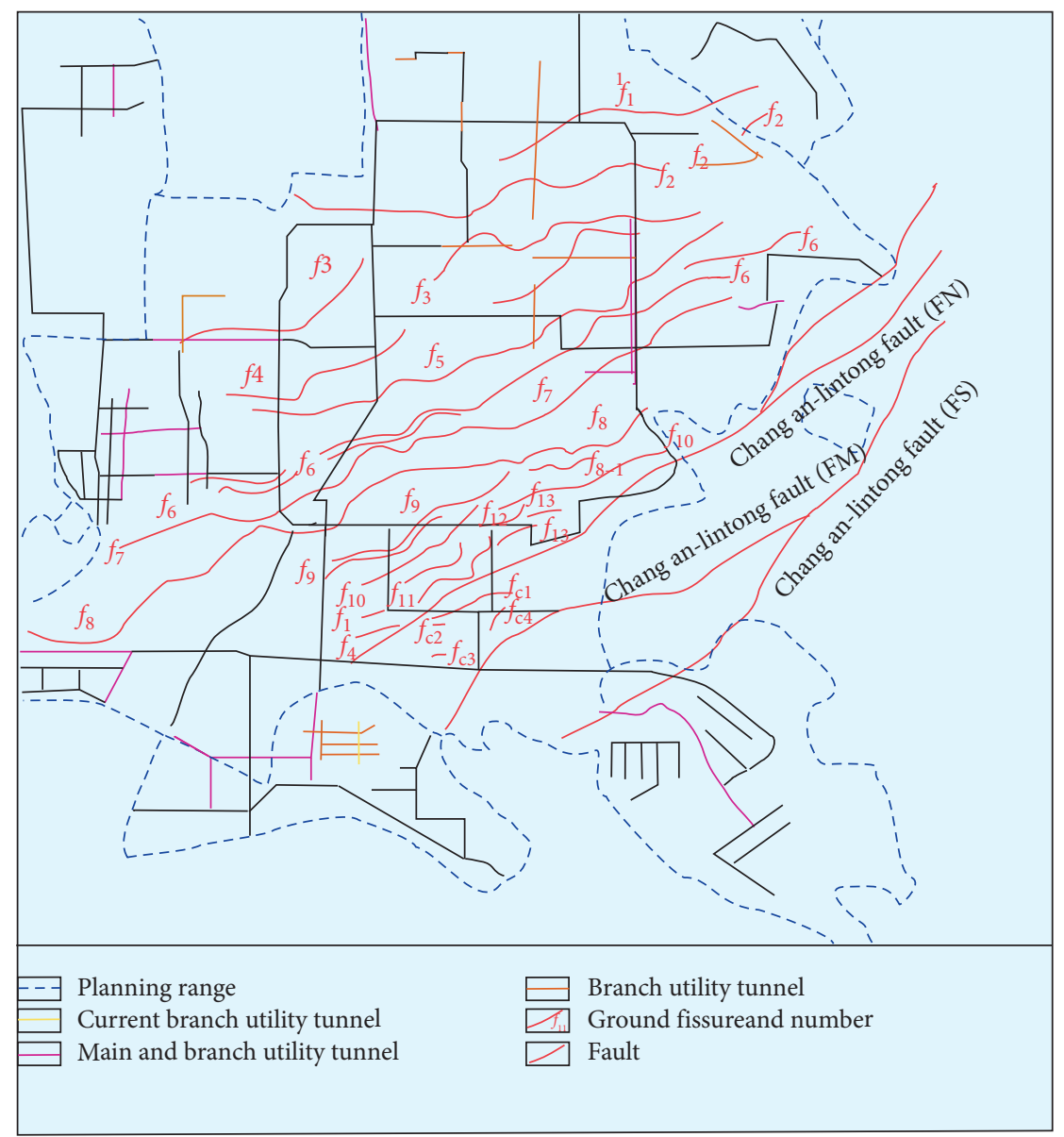

Figure 1: Xi'an underground utility tunnel and ground fissure map.

section. However, this consideration may not be sufficient to describe the actual stress on a tunnel crossing a ground fissure. Huang Qiangbing et al. used a model test and determined that ground fissure activity significantly increased vertical load on the top of the tunnel in the hanging wall area and decreased load in the foot wall area [26]. Kailing et al. obtained similar results through physical model tests [27]. Yuxiang et al. studied the vertical earth pressure of subway tunnels under normal working conditions (nonground fissure section), but they did not estimate the additional load caused by ground fissures [28-30]. This study analyzed physical model test results of a utility tunnel in a ground fissure environment to establish a vertical load calculation model of a utility tunnel under a ground fissure environment. This method provides a reference for utility tunnel design in a ground fissure zone.

\section{Xi'an Ground Fissure Activity}

Ground fissures in Xi'an generally exhibit normal fault-type peristaltic movement, where the hanging wall always slides relative to the foot wall and the vertical displacement results in unidirectional accumulation. The activity profile characteristics of the ground fissure zone in the study area are shown in Figure 2. The overall ground fissure tends to the south, and the dip angle is steep, generally above $70^{\circ}$ [31].
The ground fissure zone has the basic characteristics of three-dimensional spatial movement, including vertical displacement, horizontal displacement caused by northsouth tension, and horizontal dislocation, at a ratio of 1 : $0.31: 0.03$ [32]. When a structure obliquely crosses a ground fissure, the activity of the ground fissure will cause the structure to generate three-dimensional spatial displacement motion, with vertical, transverse, and axial displacement components. Therefore, when a utility tunnel crosses a ground fissure zone, the structural design does not need to consider the effect of the tensile and torsional components of the ground fissure but only the effect of the vertical displacement of the ground fissure.

\section{Load Calculation of Ground Fissure in Utility Tunnel Structure}

The model test was designed with a geometrical scale of 1 : 15. The stress and deformation mechanism of an underground utility tunnel caused by the displacement of a ground fissure was simulated with one end of the utility tunnel model placed at the foot wall and the other on the hanging wall. The schematic diagram of the physical model is shown in Figure 3. The foot wall was fixed, and the hanging wall was moved relative to the foot wall to simulate ground fissure displacement, with a self-locking jack that artificially 


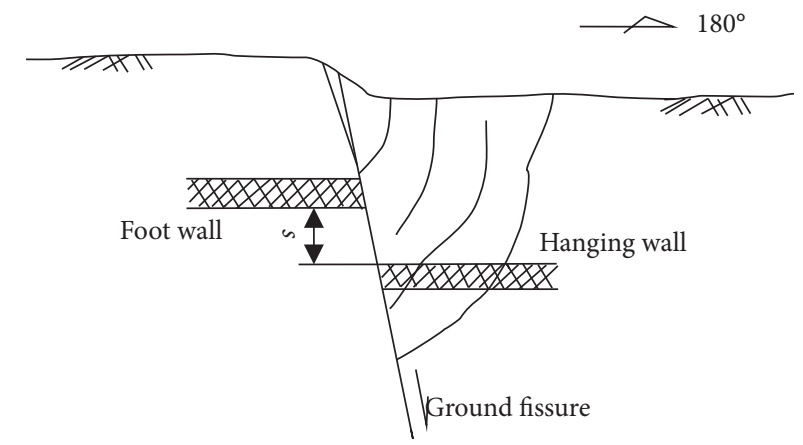

FIGURE 2: Movement section of ground fissure [25].

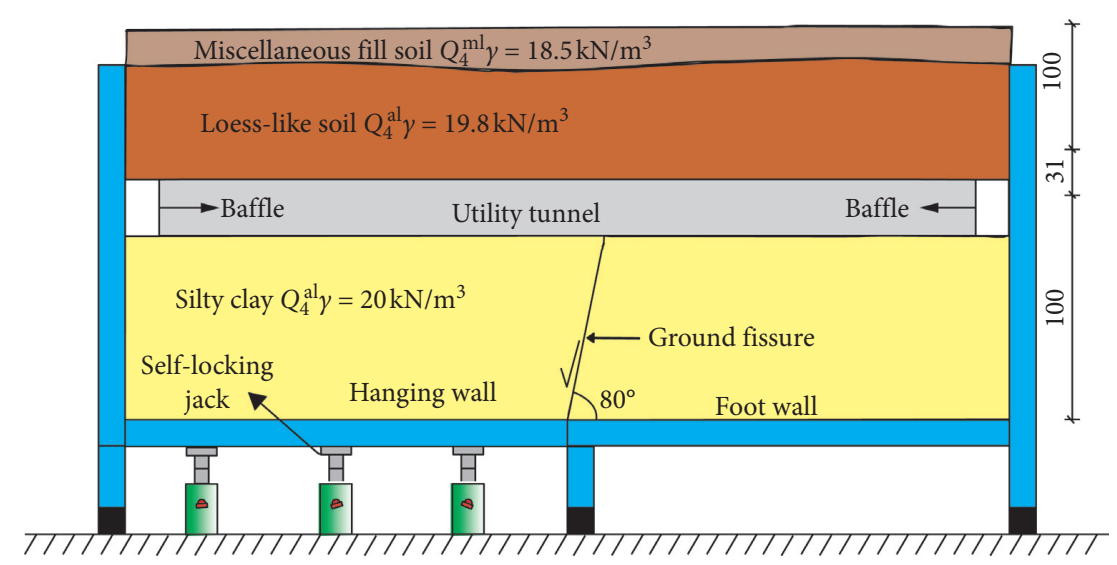

(a)

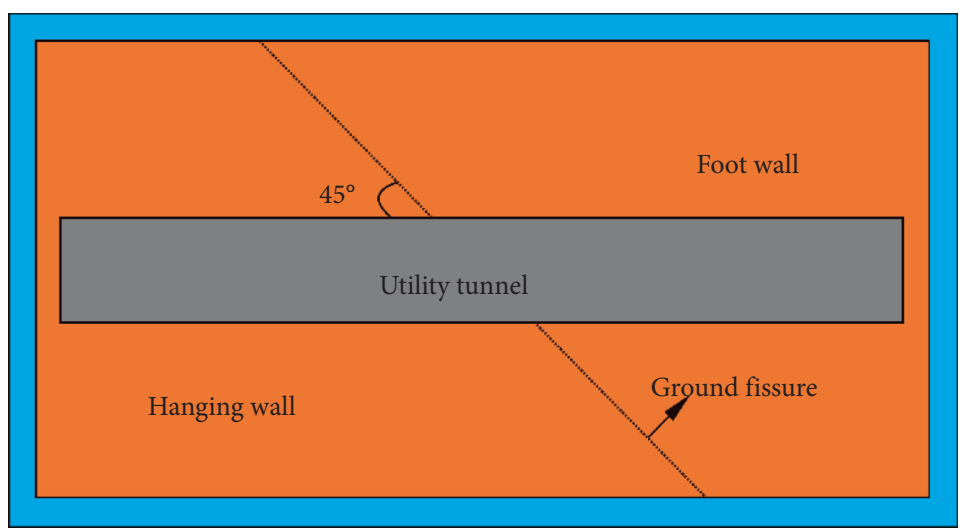

(b)
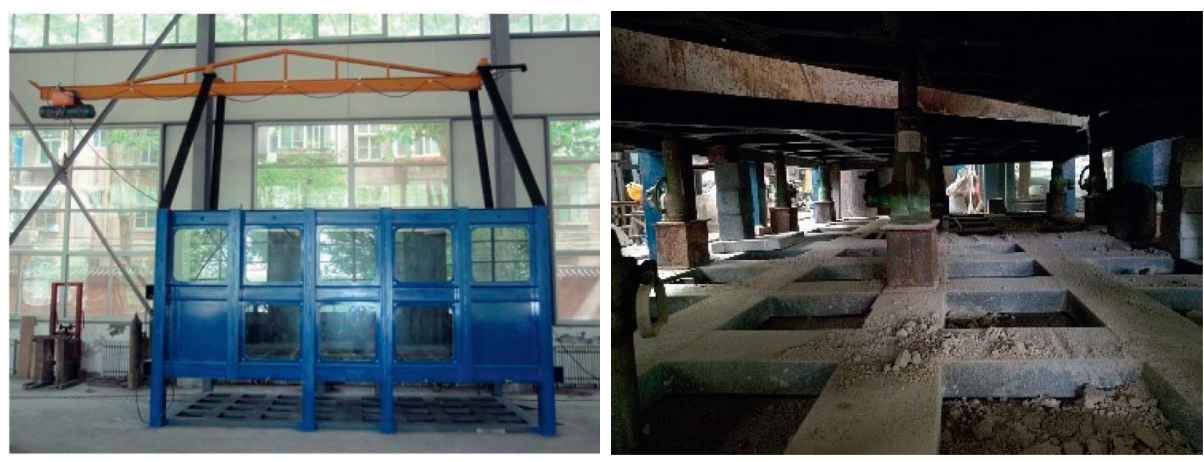

(c)

Figure 3: Diagram of ground fissure and utility tunnel (cm). (a) Model of ground fissure and utility tunnel structure (cm). (b) Schematic diagram of oblique crossing of ground fissure and utility tunnel structure. (c) Picture of model box and self-locking jack. 
controlled the overall decline of the hanging wall. The test device consisted of a lifting system, model box, and data monitoring and acquisition systems. Lifting was realized by self-locking jacks and the data monitoring system included displacement sensors, deformation sensors, and small earth pressure boxes.

Using the model, the ground fissure was filled with fine sand, with an inclination of $80^{\circ}$ and intersection with the structural axis at $45^{\circ}$. The ground fissure was set from the bottom of the model box to the bottom of the structure with a total depth of $1.0 \mathrm{~m}$. The ground fissure movement rate was $1 \mathrm{~cm} / \mathrm{d}$ ( $1 \mathrm{~cm}$ drop per day), data collected after each drop of $1 \mathrm{~cm}$ and stabilized for $12 \mathrm{~h}$, with sequentially increased drops to simulate increased ground fissure activity. The hanging wall was displaced relative to the foot wall for ground fissure displacement, with eight levels of settlement, $s=9,19,30,40,50,60,70$, and $80 \mathrm{~mm}$, and with the ground fissure displacement of $1.2 \mathrm{~m}$, twice the maximum value of ground fissure settlement in this region for a century $[31,33]$.

At distances of 1 and $1.4 \mathrm{~m}$ from the bottom of the model box, a small earth pressure box was placed at the bottom and top of the utility tunnel model to measure the contact earth pressure of the surrounding soil under different displacements. Changes in the earth pressure of the surrounding soil were measured with the measurement point arrangement shown in Figure 4.

According to the model test, there is contact earth pressure at the top of the structure. With the increase in the settlement of the hanging wall, the utility tunnel structure prevents the strata from moving downward within a certain range at the top of the structure, and soil on both sides of the structure will drag the structure downward. This will cause increased contact earth pressure on the hanging wall and decreased pressure at the foot wall. In Figure 5, $H$ is the height of the overlying soil on the utility tunnel structure and $s$ is the amount of displacement of the ground fissure. There is increased range of the hanging wall at $0.3-1.5 \mathrm{~m}$ and decreased range of the foot wall at $0.3-0.8 \mathrm{~m}$. As shown in Figure 5 a maximum contact earth pressure of $90 \mathrm{kPa}$ was measured at the top of the structure, at the end of the hanging wall. The vertical earth pressure of the overlying soil of the underground structure was $81.9 \mathrm{kPa}$ according to the conventional calculation method (see Design Specification Load Calculation Method section). The activity of the ground fissure changed the stress field on the top of the structure, and the vertical load on the top of the structure differs from the conventional ground load, resulting in additional loads. The utility tunnel is a shallow buried structure, and the principle of stress transmission can be used to calculate the formation load at the top of the structure.

The settlement deformation mode and the axial force mode of the utility tunnel structure in the ground fracture zone are shown in Figures 6 and 7. In the utility tunnel, the structure located in the foot wall shows the largest deformation near the ground fissure. The closer the structure is to the ground fissure, the larger the deformation of the utility tunnel. The deformation is close to zero far from the ground fissure. The influence of the movement of the soil body on the hanging wall will cause the utility tunnel structure located on the hanging wall to sink, and the bottom of the utility tunnel will break away from the soil, resulting in a void zone. The void zone of the physical model test is shown in Figure 8. The utility tunnel structure is similar to the overhanging beam fixed in the foot wall.

In Figure 7, $q_{1}(x)$ and $q_{2}(x)$ represent the stratum load at the top of the structure, at the hanging and foot walls, respectively. The physical model test results show that $q_{2}(x)>$ $q_{1}(x)$, and $q_{2}(x)$ is greater than the overburden earth pressure $\sigma=\gamma H$. In consideration of the safety of structural design, $q_{2}(x)$ is considered the ground load of the tunnel structure across the ground fissure segment. In order to simplify the calculation, we assume a uniform load distribution on the tunnel structure in this segment.

Analysis of the force pattern of the utility tunnel structure under ground fissure activity and classical soil mechanics theory allows proposal of a strata-holding effect calculation method. The accuracy of this method was next compared with a load calculation method that is based on the Marston principle and a calculation method of formation load.

3.1. Ground Fissure Load Calculation Method Based on Stratum Holding. In the activity environment of a ground fissure, when the hanging wall falls, the stiffness of the utility tunnel structure itself will prevent the downward movement of the soil mass on the top within a certain range. The surrounding soil on both sides of the utility tunnel structure exerts a certain downward drag effect on the utility tunnel structure. The overall load diagram of the utility tunnel structure is shown in Figure 9. The forces acting on the surrounding rock FEGH are the gravity $W_{1}$ of the stratum soil, the holding force $T_{1}$ of the prism ACE and BDF acting on FEGH on both sides of the surrounding rock, and the reaction force $P$ exerted by the utility tunnel structure. Assuming uniform stress on the upper part of the utility tunnel structure, the cross section was analyzed, as shown in Figure 10. In Figure 10, $W_{1}$ is the weight of the soil FEGH; $W_{2}$ is the weight of the ACE and BDF; $T$ is the friction along the sliding surface; and $F$ is the supporting force of the soil $\mathrm{ACE}$ and BDF.

Considering side BFD, the force diagram is shown in Figure 9(b). In the figure, $W_{2}$ is the weight of the side, and its size is related to the fracture angle $\beta$ of the strata.

$$
W_{2}=\frac{1}{2} \times|B F| \times|D F|=\frac{1}{2} \gamma(H+D) \frac{1}{\tan \beta} .
$$

In the formula, $\gamma$ is the gravity of surrounding soil $(\mathrm{kN} /$ $\left.\mathrm{m}^{3}\right), H$ is the utility tunnel depth (m), and $D$ is the height of the utility tunnel.

The fracture surface $\mathrm{AD}$ and $\mathrm{BC}$ are considered the back of the retaining wall, and the soil $\mathrm{ABCD}$ will generate active 

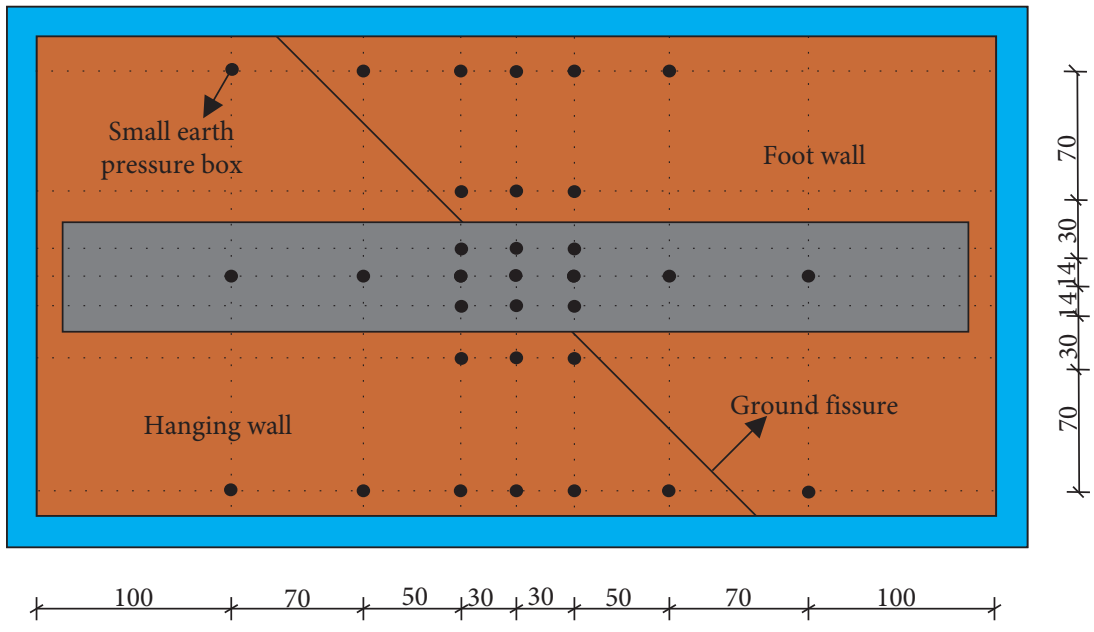

FiguRE 4: Earth pressure cells layout $(\mathrm{cm})$.

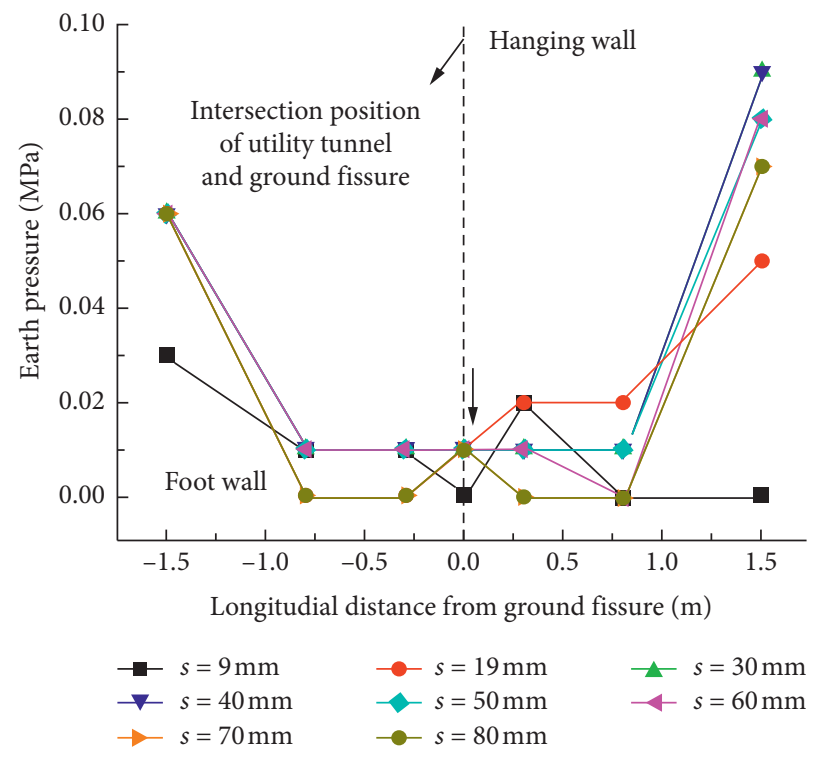

FigURE 5: Variation of top contact pressures of the utility tunnel crossing the ground fissure section $(H=4.5 \mathrm{~m})$.

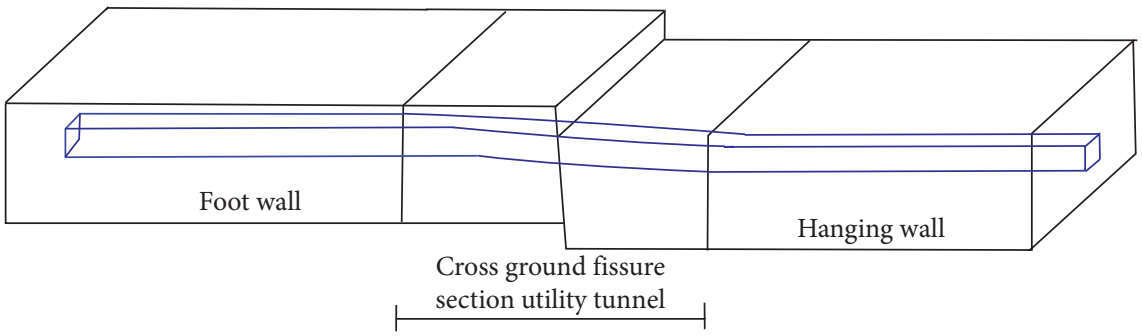

Figure 6: Sinking model of the utility tunnel crossing ground fissure section. 


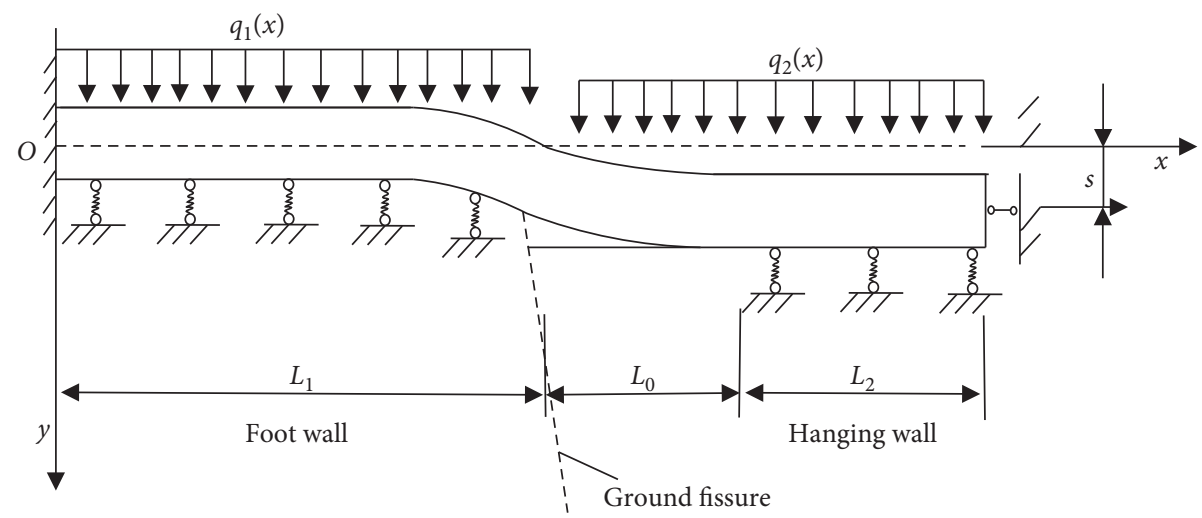

FIGURE 7: Load pattern of the utility tunnel crossing ground fissure section.

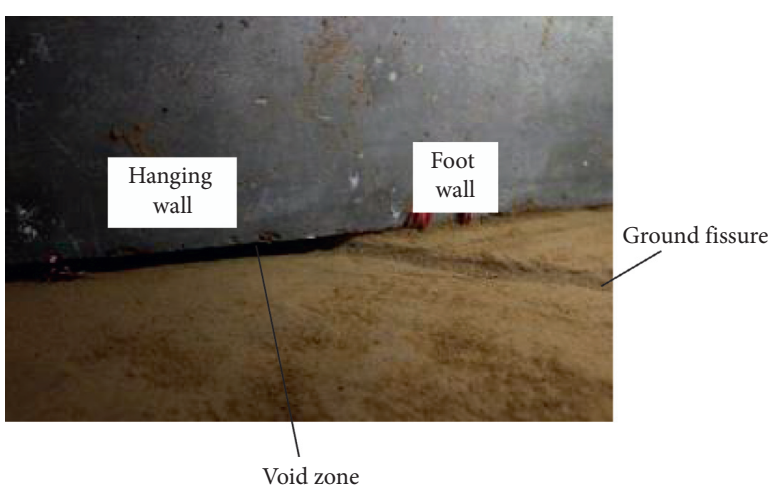

(a)

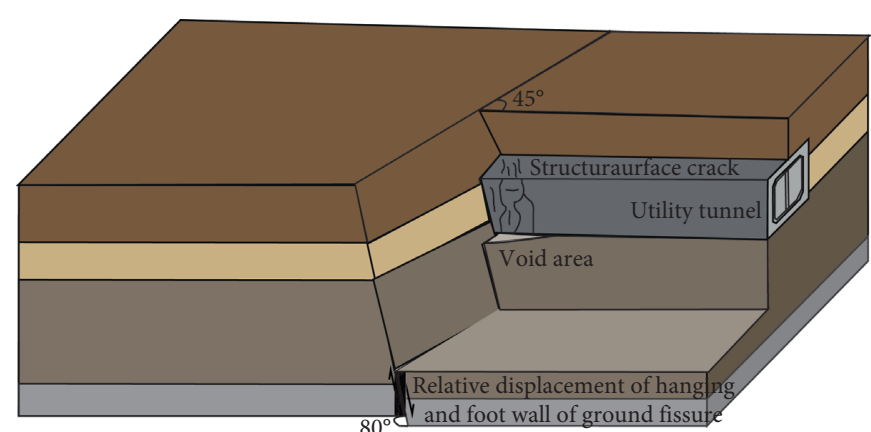

(b)

Figure 8: Physical model test of the ground fissure section utility tunnel void zone. (a) Model test void zone. (b) Model test void zone.

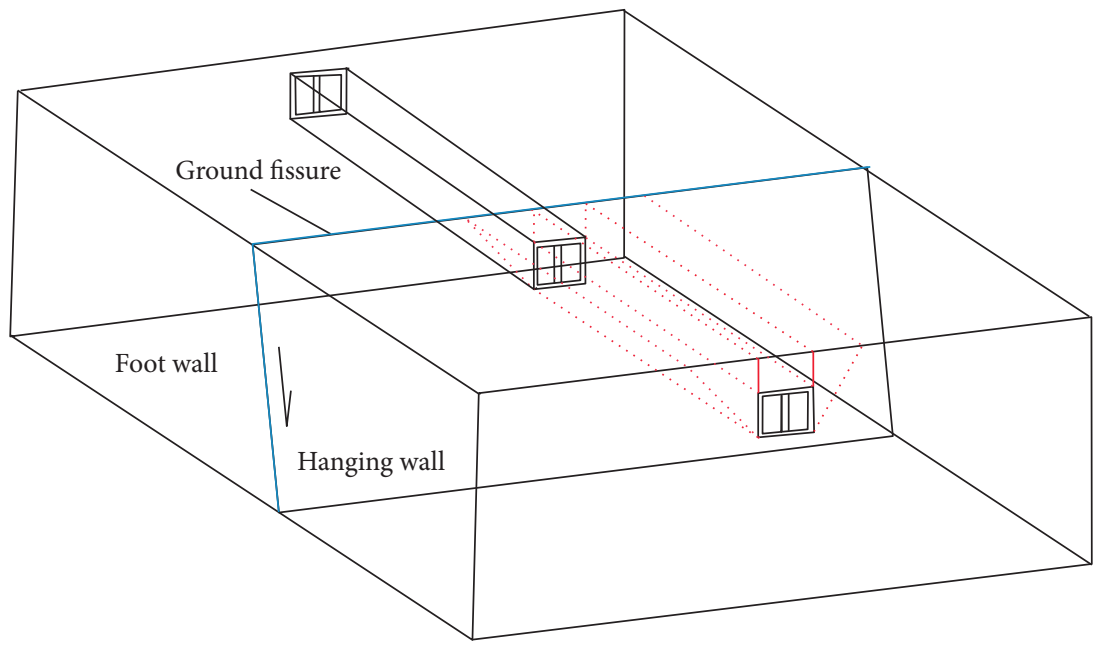

(a)

Figure 9: Continued. 


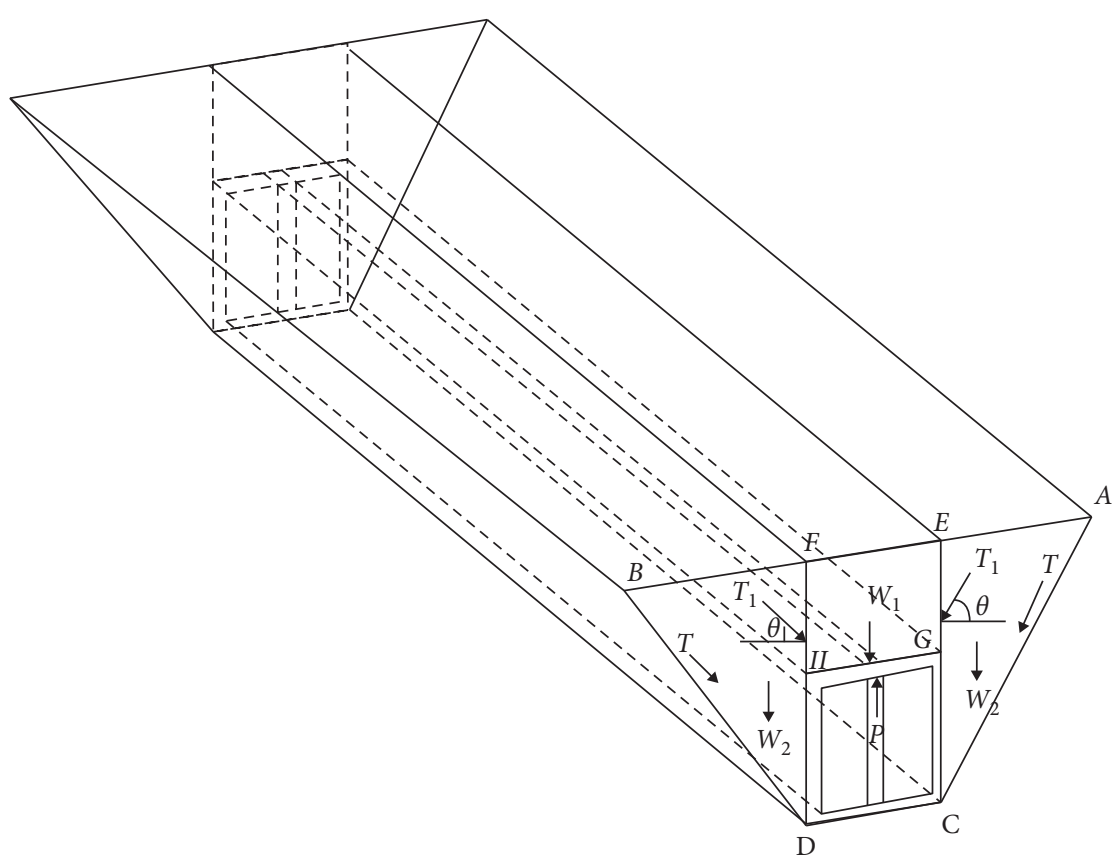

(b)

FIGURE 9: Calculation model of interaction between the utility tunnel and Earth in the hanging wall of ground fissure. (a) Structural overall diagram. (b) Structural hanging wall force mode.

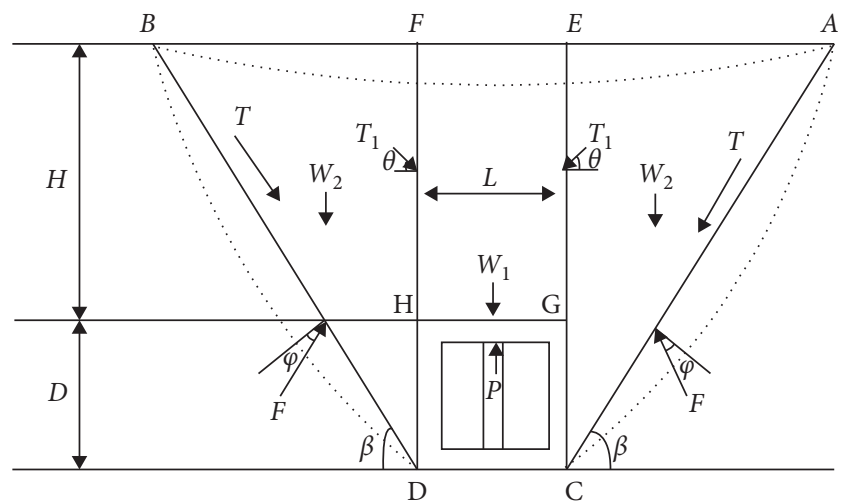

(a)

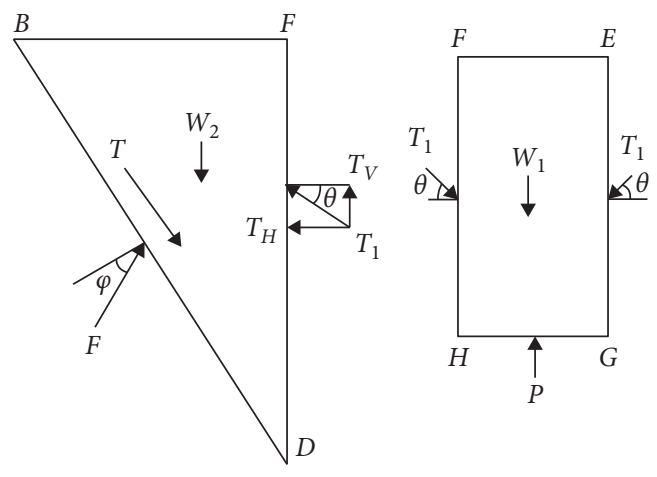

(b)

FIGURE 10: Calculation model of the surrounding pressure of the utility tunnel under ground fissure environment. (a) Structural disk force mode. (b) Force diagram of BFD and FEGH.

earth pressure for $\mathrm{AD}$ and $\mathrm{BC}$, respectively. According to the Coulomb earth pressure,

$$
F=\frac{1}{2 \gamma}(H+D)^{2} \lambda .
$$

In the formula,

$$
\begin{aligned}
\lambda & =\frac{\sin (\beta-\varphi)}{\tan \beta \cos [\beta-(\theta+\varphi)]} \\
& =\frac{1-\tan \varphi \cot \beta}{\tan \beta[(\cos \theta-\sin \theta \tan \varphi) \cot \beta+\sin \theta+\cos \theta \tan \varphi]} .
\end{aligned}
$$


So,

$$
T=F \cos \varphi \times f .
$$

Take the friction coefficient as $f=\tan \varphi$, then

$$
T=F \sin \varphi .
$$

It can be known from force balance of BFD in Figure 9(b):

$$
T_{1}=\frac{1 / 2 \gamma(H+D)^{2}\left[1 / \tan \beta+\lambda \sin \varphi \cos \left(90^{\circ}-\beta\right)-\lambda \sin \left(45^{\circ}+(\varphi / 2)\right)\right]}{\sin \theta} .
$$

In this formula, $\varphi$ is the inner friction angle of surrounding soil and $\theta$ is the friction angle on both sides of the soil at the top of the utility tunnel.

A utility tunnel structure is generally shallow and the surrounding rock is mainly soil, so the surrounding rock level is VI. No corresponding criterion is included in the utility tunnel specification, but the value of $\theta$ can be within the range $(0.3 \sim 0.5) \varphi$ as suggested in subway specifications [34].
In formula (6), $\lambda$ is the lateral pressure coefficient and $\beta$ is the rupture angle of the surrounding rock. The value of $\beta$ can be calculated from the theory of active earth pressure:

$$
\beta=45^{\circ}+\frac{\varphi}{2} \text {. }
$$

For FEGH on the soil column at the top of the utility tunnel structure, a force diagram was drawn, as shown in Figure $8(\mathrm{~b}) . T_{1}$ is the holding force, which changes in the following range with different construction methods:

$$
\begin{array}{r}
\frac{1 / 2 \gamma H^{2}\left[1 / \tan \beta+\lambda \sin \varphi \cos \left(90^{\circ}-\beta\right)-\lambda \sin \left(45^{\circ}+(\varphi / 2)\right)\right]}{\sin \theta} \leq T_{1} \\
\leq \frac{1 / 2 \gamma(H+D)^{2}\left[1 / \tan \beta+\lambda \sin \varphi \cos \left(90^{\circ}-\beta\right)-\lambda \sin \left(45^{\circ}+(\varphi / 2)\right)\right]}{\sin \theta} .
\end{array}
$$

Take $T_{1}$ as

$$
T_{1}=\frac{1 / 2 \gamma H^{2}\left[1 / \tan \beta+\lambda \sin \varphi \cos \left(90^{\circ}-\beta\right)-\lambda \sin \left(45^{\circ}+(\varphi / 2)\right)\right]}{\sin \theta} .
$$

According to the equilibrium condition, the total vertical pressure $P$ of the surrounding rock can be obtained as $P=W_{1}+2 T_{1} \sin \theta$.

Then, the vertical earth pressure load along the unit length of the utility tunnel structure can be determined as

$$
q=\frac{P}{L}=\frac{W_{1}+2 T_{1} \sin \theta}{L} .
$$

3.2. Ground Fissure Load Calculation Method Based on Marston [35] Principle. Under the activity environment of a ground fissure, the soil mass of the hanging wall will cause settlement. With a utility tunnel structure, the soil mass at the top of the structure located in the hanging wall of the ground fissure will settle more slowly than the surrounding soil mass, and the surrounding soil mass will exert downward friction on the soil mass at the top of the structure. This kind of stress characteristic is similar to the earth pressure of the buried pipeline studied by Marston. So Marston's principle of calculating the earth pressure of the buried pipeline with ultimate equilibrium conditions can be used to solve the vertical formation pressure or load of the utility tunnel structure under the action of a ground fissure.

Figure 11 shows the vertical earth pressure calculation model for the utility tunnel structure located on the hanging wall under the action of ground fissure. According to the Marston principle, the soil at the top of the structure on the hanging wall is displaced relative to the surrounding soil under ground fissure action. The sliding failure surface is in the vertical plane aa 'and $b^{\prime}$ ', and the utility tunnel structure is buried deeply to $H$, and the structural cross section height and width are $D$ and $L$. When the hanging wall is lowered, the soil showed a downward drag effect on the structure, forming a downward shear force $\tau$ that is equal to the shear strength of the soil $\tau_{f}$. The stress distribution of the $\mathrm{d} z$ thickness stratum at the depth of $z$ was analyzed, as shown in Figure 10. The formation microelement weight force is $\mathrm{d} W=\gamma L \mathrm{~d} z$, and the lateral earth pressure is $\sigma_{h}=K \sigma_{z}$, so then the shear strength is $\tau_{f}=c+\sigma_{h}$ on the fracture surface $a a^{\prime}$ and $b b^{\prime}$. 


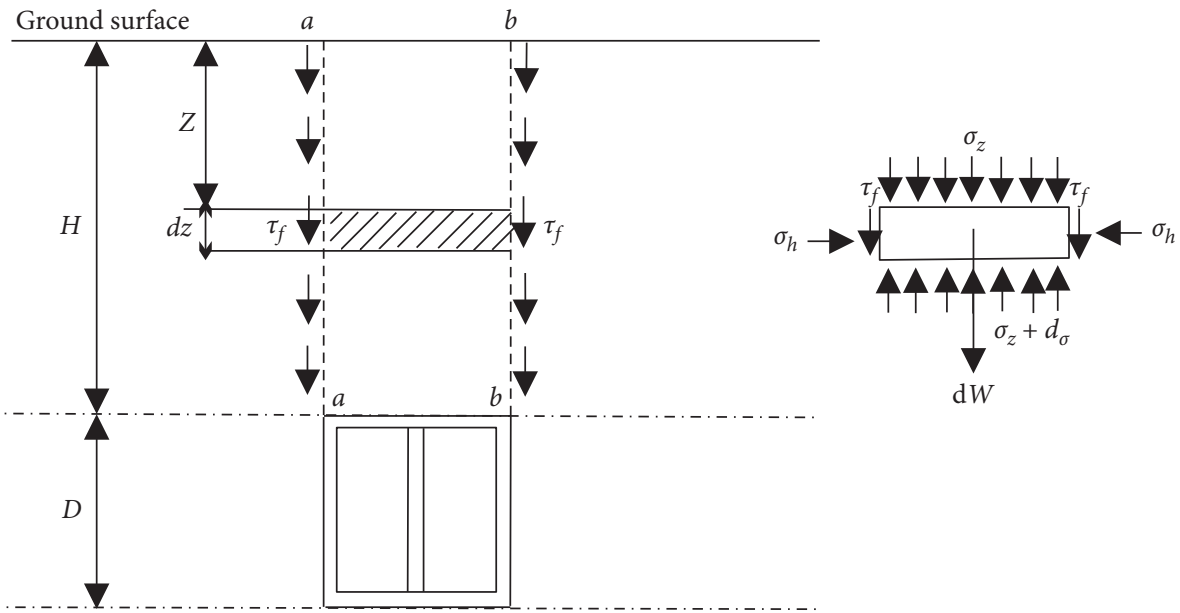

Figure 11: Calculation model of vertical earth pressure on the top of the utility tunnel in the hanging wall of ground fissure.

According to the static equilibrium of the vertical layer microelement,

$$
\mathrm{d} W=L \sigma_{z}+2 \tau_{f} \mathrm{~d} z=L\left(\sigma_{z}+\mathrm{d} \sigma_{z}\right)
$$

Then,

$$
\gamma L \mathrm{~d} z+2\left(K \sigma_{z} \tan \varphi+c\right)-L \mathrm{~d} \sigma_{z}=0 .
$$

In formula (12), $\gamma$ is the gravity of the stratum $\left(\mathrm{kN} / \mathrm{m}^{3}\right) ; c$ and $\varphi$ are the cohesive force and internal friction angle of the soil, respectively; and $K$ is the earth pressure coefficient and is between the active earth pressure coefficient $K_{\mathrm{a}}$ and the refined earth pressure coefficient $K_{\mathrm{o}}$. Marston uses the active earth pressure coefficient $K_{\mathrm{a}}$. From formula (9),

$$
\frac{\mathrm{d} \sigma_{z}}{\mathrm{~d} z}=\frac{2 K \tan \varphi}{L} \sigma_{z}+\gamma+\frac{2 c}{L} .
$$

Formula (13) is a first-order differential equation. According to the boundary conditions $z=0$ and $\sigma_{z}=0$, the vertical earth pressure at the depth $z$ can be obtained:

$$
\sigma_{z}=\frac{L(\gamma+(2 c / L))}{2 K \tan \varphi}\left(e^{2 K(z / L) \tan \varphi}-1\right) .
$$

When the buried depth of the structure is $H$, the vertical earth pressure at the top of the structure can be obtained.

$$
\sigma_{z}=\frac{L(\gamma+(2 c / L))}{2 K \tan \varphi}\left(e^{2 K(H / L) \tan \varphi}-1\right) .
$$

Then, the total earth pressure (load) at the top of the structure under the action of the ground fissure is as follows:

$$
G=\sigma z L \text {. }
$$

3.3. Design Specification Load Calculation Method. Article 7.3.2 of the Design Standard for Urban Utility Tunnel of Shaanxi Province (DBJ61/T 125-2106) stipulates the forces on a structure including structural self-weight, earth pressure, water pressure with constant water level, prestressing, pipeline steady-state water weight, water weight in gravity flow pipes, concrete shrinkage, and ground deformation. According to standard [34], the earth pressure is a permanent load and can be calculated as follows.

The structure of a utility tunnel is generally considered in terms of the weight of all soil columns on the calculated section. The specification does not specifically include any additional loads caused by ground fissure activities. This method can be used to calculate the vertical earth pressure on a utility tunnel structure as follows:

$$
\sigma_{z}=\sum_{n}^{i=1} \gamma_{i} h_{i}
$$

In formula (13), $\gamma_{i}$ is the gravity of the $i$-th layer of soil $(\mathrm{kN} / \mathrm{m} 3)$, and for lower than groundwater level, the saturated gravity density calculation should be used; $h_{i}$ is the thickness of the $i$-th layer of soil $(m)$. When the stratum changes little and is more uniform, the vertical earth pressure can also be approximated by the average gravity multiplied by the buried depth of the pipe structure.

\section{Comparison of Methods and Discussion}

The buried depth of the utility tunnel is $4.5 \mathrm{~m}$, a shallow buried structure, as shown in Figure 12. According to a geological survey report, the average gravity of the inner layer within this buried depth range is $18.2 \mathrm{kN} / \mathrm{m}^{3}$, the cohesive force of the stratum soil is $25 \mathrm{kPa}$, and the internal friction angle is 24 . Height $L$ and the buried depth $H$ of the utility tunnel in the ground fracture section are 4.7 and $4.5 \mathrm{~m}$, as shown in Figure 12. The model test results were compared with the ground fissure load calculation method using the stratum holding effect and the calculation method based on the Marston principle. The results are shown in Table 1.

As shown in Table 1, the calculated value was largest when calculated based on the Marston principle, followed by the calculated value based on the stratum holding effect. The design specification method does not consider any additional load caused by the ground fissure, so the calculated value is the smallest for this model. The results for the model 


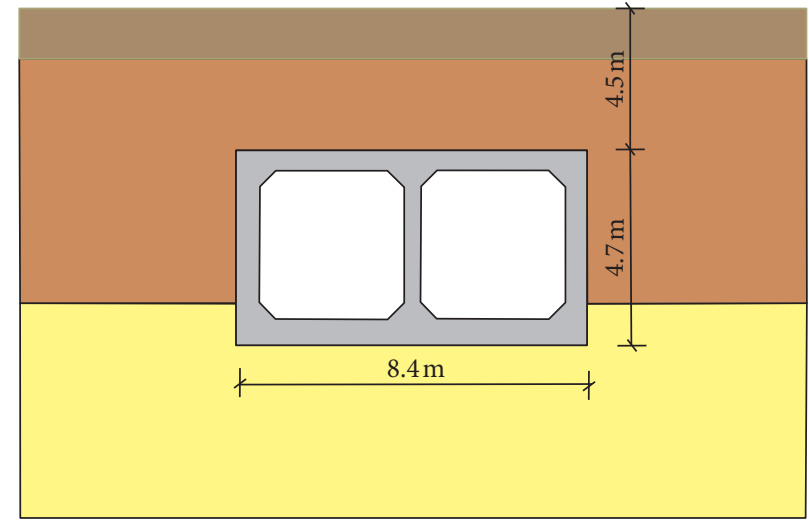

FIGURE 12: Schematic diagram of utility tunnel structure and burial depth.

TABLE 1: Comparison of results for theoretical analysis and model test.

Vertical pressure value $(\mathrm{kPa})$

$\begin{array}{lcccc}\text { Utility tunnel buried depth } & \text { Based on stratum holding } & \begin{array}{c}\text { Based on the Marston } \\ \text { principle }\end{array} & \begin{array}{c}\text { Model test } \\ \text { result }\end{array} & \begin{array}{c}\text { Design specification calculation } \\ \text { method }\end{array}\end{array}$

4.5

94.83

124.67

90

81.9

test and calculations based on the stratum holding effect method are relatively close but not identical. This slight difference may reflect gravity deviations in the model tests and the prototype structural engineering site. The model test and the prototype structural stress field are similar but not identical.

As shown in Figure 11, Marston's principle assumes that the rupture surface on both sides of the top of the structure is a vertical plane, which deviates from the failure situation of the surrounding soil around the top of the structure under actual ground fissure activity. According to the model test results, the rupture surface of the soil is an inclined plane (as shown in Figure 13). Based on the calculation method based on the stratum holding effect, the fracture surface is considered as an inclined plane, with a fracture angle of $45^{\circ}+{ }^{\circ} \varphi /$ 2 . This more accurately reveals the actual failure mode, so the calculation result is closer to the actual situation.

In conclusion, when there is ground fissure activity, the vertical stratum load of a utility tunnel structure on the hanging wall cannot be calculated using the conventional stratum load, as the additional load caused by ground fissure activity should be considered. Thus, the calculation method based on the stratum holding effect should be adopted in the design of a utility tunnel structure across a ground fissure zone. For the foot wall of the ground fissure where the vertical formation pressure is reduced (as shown in Figure 5), there is less vertical load at the top of the structure than that for on an area lacking a ground fissure. To increase design safety, the weight of all the soil columns above the calculated section should be considered. The approach described here allows the calculation of the vertical earth pressure in the hanging and foot walls of a section of the utility tunnel that crosses a ground fissure zone. Due to changing vertical load of the structure section, variable

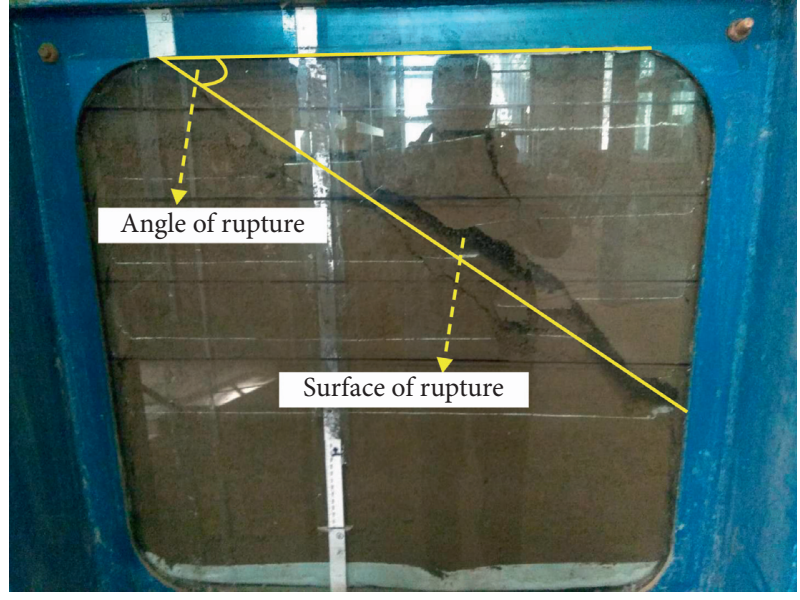

Figure 13: Model test soil rupture angle.

design can be considered for a utility tunnel structure in a region with ground fissure.

\section{Conclusion}

Using the results of physical model tests, a stress model for a utility tunnel structure under the action of ground fissures was analyzed. Through comparative analysis and discussion of the calculation method of the vertical stratum load of the utility tunnel structure, the following conclusions are drawn:

(1) An active ground fissure will cause additional load, which differs from the normal stratum environment. The additional load caused by a ground fissure should be considered as part of the stratum load of a utility tunnel structure in a ground fissure area. 
(2) In a ground fissure environment, compared with the Marston principle calculation method and the standard calculation method, the ground fissure load calculation method based on the stratum holding effect is more accurate and is a better way to analyze the failure mode.

\section{Data Availability}

All data generated or analyzed during this study are included in the article.

\section{Conflicts of Interest}

The authors declare that they have no conflicts of interest.

\section{Acknowledgments}

The work described in this article is part of a research project on the "seismic response and seismic mitigation measures for utility tunnel structure under trans-ground fissure" funded by the "Key Research and Development Program of Shaanxi Province" under grant no. 2017ZDXM-SF-095 and "the formation mechanism and evolution process of passive soil-arch effect in front of cantilever rectangular antislide piles in the loess area" funded by the "National Natural Science Foundation of China" under grant no. 41877285.

\section{References}

[1] T. L. Holzer, "Ground failure induced by ground-water withdrawal from unconsolidated sediment," Reviews in Engineering Geology, vol. 6, pp. 67-106, 1984.

[2] G.-Y. Wang, G. You, J.-Q. Zhu, J. Yu, and W. Li, "Earth fissures in su-xi-chang region, Jiangsu, China," Surveys in Geophysics, vol. 37, no. 6, pp. 1095-1116, 2016.

[3] J. Peng, J. Qiao, Y. Leng, F. Wang, and S. Xue, "Distribution and mechanism of the ground fissures in wei river basin, the origin of the silk road," Environment. Earth Sciences. Germany, vol. 75, no. 8, pp. 1-12, 2016.

[4] L. Ayalew, H. Yamagishi, and G. Reik, "Ground cracks in Ethiopian rift valley: facts and uncertainties," Engineering Geology, vol. 75, no. 3-4, pp. 309-324, 2004.

[5] C. F. Lee, J. M. Zhang, and Y. X. Zhang, "Evolution and origin of the ground fissures in Xian, China," Engineering Geology, vol. 43, no. 1, pp. 45-55, 1996.

[6] Y. L. Li, J. C. Yang, and X. M. Hu, "Origin of ground fissure in the Shanxi graben system, northern China," Engineering Geology, vol. 55, no. 4, pp. 267-275, 2000.

[7] E. Rojas, J. Arzate, and M. Arroyo, "A method to predict the group fissuring and faulting caused by regional groundwater decline," Engineering Geology, vol. 65, no. 4, pp. 245-260, 2002.

[8] J. W. Bell, J. G. Price, and M. D. Mifflin, "Subsidence induced fissuring along preexisting faults in Las Vegas Nevada," in Proceedings of the 35th Annual Meeting of the Association of Engineering Geologist, Association of Engineering Geologists, Long Beach, CA, USA, October 1992.

[9] J. Pacheco, J. Arzate, E. Rojas, M. Arroyo, V. Yutsis, and G. Ochoa, "Delimitation of ground failure zones due to land subsidence using gravity data and finite element modeling in the Querétaro valley, México," Engineering Geology, vol. 84, no. 3-4, pp. 143-160, 2006.

[10] X. Li, S. J. Wang, T. Y. Liu, and F. S. Ma, "Engineering geology, ground surface movement and fissures induced by underground mining in the Jinchuan Nickel Mine," Engineering Geology, vol. 76, no. 1-2, pp. 93-107, 2004.

[11] L. D. Filippis, E. Anzalone, A. Billi, C. Faccenna, P. P. Poncia, and P. Sella, "The originand growth of a recently-active fissure ridge travertine over a seismic fault, Tivoli, Italy," Geomorphology, vol. 195, pp. 13-26, 2013.

[12] T. L. Holzer, "State and local response to damaging land subsidence in United States urban areas," Engineering Geology, vol. 27, no. 1-4, pp. 449-466, 1989.

[13] S. S. El Baruni, "Earth fissures caused by groundwater withdrawal in sarir south agricultural project area, Libya," Hydrogeology Journal, vol. 2, no. 1, pp. 45-52, 1994.

[14] M. A. Laike, "Environmental hazard from fissures in the main Ethiopian Rift," Journal of African Earth Sciences, vol. 27, no. 3-4, pp. 481-490, 1998.

[15] F. M. Williams, M. A. J. Williams, and F. Aumento, “Tensional fissures and crustal extension rates in the northern part of the Main Ethiopian Rift," Journal of African Earth Sciences, vol. 38, no. 2, pp. 183-197, 2004.

[16] J.-B. Peng, L.-W. Chen, Q.-B. Huang, Y.-M. Men, W. Fan, and J.-K. Yan, "Physical simulation of ground fissures triggered by underground fault activity," Engineering Geology, vol. 155, pp. 19-30, 2013.

[17] J.-B. Peng, Q.-B. Huang, Z.-P. Hu et al., “A proposed solution to the ground fissure encountered in urban metro construction in Xi' an, China," Tunnelling and Underground Space Technology, vol. 61, pp. 12-25, 2017.

[18] M. Hernandez-Marin and T. J. Burbey, "Controls on initiation and propagation of pumping-induced earth fissures: insights from numerical simulations," Hydrogeology Journal, vol. 18, no. 8, pp. 1773-1785, 2010.

[19] R. C. Jachens and T. L. Holzer, "Differential compaction mechanism for earth fissures near Casa Grande, Arizona," Geological Society of America Bulletin, vol. 93, no. 10, pp. 998-1012, 1982.

[20] P. B. Burridge, R. F. Scott, and J. F. Hall, "Centrifuge study of faulting effects on tunnel," Journal of Geotechnical Engineering, vol. 115, no. 7, pp. 949-967, 1989.

[21] A. R. Shahidi and M. Vafaeian, "Analysis of longitudinal profile of the tunnels in the active faulted zone and designing the flexible lining (for Koohrang-III tunnel)," Tunnelling and Underground Space Technology, vol. 20, no. 3, pp. 213-221, 2005.

[22] J. B. Peng, J. W. Qiao, Y. Q. Leng, F. Y. Wang, and S. Z. Xue, "Distribution and mechanism of the ground fissures in Wei River basin, the origin of the Silk road," Environment Earth Sciences, vol. 75, no. 8, 2016.

[23] J. B. Peng, X. H. Sun, W. Wang, and G. C. Sun, "Characteristics of land subsidence, ground fissures and related disaster chain effects with respect to urban hazards in Xian, China," Environment Earth Sciences, vol. 75, no. 16, pp. 3-15, 2016.

[24] J. Peng, J. Xu, R. Ma, and F. Wang, "Characteristics and mechanism of the longyao ground fissure on north China plain, China," Engineering Geology, vol. 214, pp. 136-146, 2016.

[25] Q. B. Huang, J. B. Peng, H. W. Fan et al., "Metro tunnel hazards induced by active ground fissures in Xi' an and relevant control measures," Chinese Journal of Geotechnical Engineering, China, vol. 31, no. 5, pp. 781-788, 2009. 
[26] Q. B. Huang, J. B. Peng, Y. M. Men et al., "Model test study on effect of ground fissure on open-cut metro tunnel with integral lining," Chinese Journal of Rock Mechanics and Engineering, China, vol. 27, no. 11, pp. 2324-2331, 2008.

[27] K. L. Li, Y. M. Men, J. P. Yan et al., “Test study of interaction mechanism under metro tunnel orthogonally crossing ground fissure," Chinese Journal of Rock Mechanics and Engineering, China, vol. 30, no. 3, pp. 556-563, 2011.

[28] Y. X. Song, X. Y. Jia, and Y. Q. Zhu, "Study on vertical earth pressure calculation of metro tunnel," Chinese Journal of Rock and Soil Mechanics, vol. 28, no. 10, pp. 2 240-2 244, 2007.

[29] H. B. Li and X. H. Guo, "Research on calculation methods of earth pressure on muti-arch tunnel for highway," Chinese Journal of Rock and Soil Mechanics, vol. 30, no. 11, pp. 3 429-3 434, 2009.

[30] H. L. Fu, H. R C, H. H. Zhu, "Theoretical load solution of single tunnel inside broken rock mass," Chinese Journal of Journal of Central South University:Science And Technology, vol. 35, no. 3, pp. 478-483, 2004.

[31] J. B. Peng, Q. Zhang, Q. B. Huang et al., Hazard of Ground Fissure in Xi'an, pp. 100-200, Science Press, Beijing, China, 2012.

[32] N. Liu, Q. Huang, Y. Ma et al., "Experimental study of a segmented metro tunnel in a ground fissure area," Soil Dynamics and Earthquake Engineering, vol. 100, pp. 410-416, 2017.

[33] Q. B. Huang, J. B. Peng, Q. Y. Wang et al., "Reserved displacement for anti-crack design of metro tunnel passing through active ground fissures zones," Chinese Journal of Rock Mechanics and Engineering, China, vol. 29, no. S1, pp. 2669-2675, 2010.

[34] The National Standards Compilation Group of Peoples Republic of China, Load Code for the Design of Building Structures, China Architecture and Building Press, Beijing, China, 2006.

[35] A. Maston and A. O. Andserson, "The theory of loads on pipe in ditches and tests of cement and clay drain tile and sewer pipe," Iowa:Iowa Engineering Experiment Station Bulletin, United States Iowa State College, vol. 1913, pp. 31-181, 1913. 